\title{
Pulmonary oxidative stress in diabetic rats exposed to hyperoxia $^{1}$
}

\author{
Letícia Alves Paiva', Iandara Schettert Silva", Albert Schiaveto de Souza"', Pedro Carvalho Cassino"v
}

'Fellow Master degree, Postgraduate Program in Health and Development, West Central Region, Universidade Federal do Mato Grosso do Sul (UFMS), Campo Grande-MS, Brazil. Scientific and intellectual content of the study, manuscript preparation and writing.

"PhD, Associate Professor, Postgraduate Program in Health and Development, West Central Region, UFMS, Campo Grande-MS, Brazil. Critical revision, final approval.

IIIPhD, Associate Professor, Postgraduate Program in Health and Development, West Central Region, UFMS, Campo Grande-MS, Brazil. Analysis and interpretation of data, statistical analysis.

IVFellow PhD degree, Postgraduate Program in Health and Development, West Central Region, UFMS, Campo GrandeMS, Brazil. Technical procedures.

\section{Abstract}

Purpose: To evaluate the pulmonary oxidative stress in diabetic rats exposed to hyperoxia for 90 minutes.

Methods: Forty male Wistar rats were divided into four groups, each one containing 10 animals, according to the oxygen concentration to which they were exposed: $21 \%, 50 \%, 75 \%$ and $100 \%$ (hyperoxia). In each group five animals were randomly induced to diabetes by means of at a dose of $55 \mathrm{mg} / \mathrm{kg}$ of streptozotocin (STZ).

Results: Seventy two hours after diabetes induction, a significant difference was seen in blood glucose in the experimental groups in comparison with the control. In the experimental groups a significant difference was observed in the concentration of malondialdehyde (MDA) in lung tissue and blood plasma ( $p<0.05)$, except the 50\% group. In the control group, significant differences in the MDA concentration in plasma and lung tissue were also observed $(p<0.05)$, except the $75 \%$ group. The MDA concentration in lung tissue in comparison with the diabetic and non-diabetic groups showed a significant difference in the $21 \%$ group; however, no difference was seen in the 75 and $100 \%$ groups.

Conclusion: In diabetic animals high oxygen concentrations (75 and 100\%) do not appear to exert deleterious effects on lipid peroxidation in lung tissue.

Key words: Diabetes Mellitus, Experimental. Streptozocin. Oxidative Stress. Lung. Oxygen. Rats. 


\section{Introduction}

Diabetes Mellitus is a group of metabolic diseases characterized by hyperglycemia resulting from disorders in insulin secretion, insulin action or both. Chronic hyperglycemia in diabetes is associated with long-term damage, dysfunction and failure of various organs, especially eyes, kidney, heart, nerves and blood vessels ${ }^{1}$. Diabetes Mellitus is considered a complex and chronic disorder difficult to diagnose that develops gradually.

In 2011, the estimated population of people suffering from diabetes was 366 million. In 2030, there will probably be a $50.7 \%$ increase in the number of people with diabetes worldwide, maybe because of population growth, population aging, or urbanization associated with lifestyle change. The expected global raise in the number of people with diabetes projected for the period 2011-2030 is a mean annual growth rate of $2.7 \%$, which corresponds to 1.7 times the total annual growth rate of the world adult population.

In Brazil, in 2011, the number of people with diabetes aged 29-79 was 12.4 million; the estimate for 2030 is 19.6 million diabetics ${ }^{2}$.

The studies of Davis et al. ${ }^{3}$ and Walter et al. ${ }^{4}$ demonstrated that DM causes functional abnormalities in the pulmonary system, such as a reduction in elastic recoil, volumes and diffusion capacity. As reviewed by Brownlee ${ }^{5}$, hyperglycemia triggers oxidative stress by increasing the production of mitochondrial superoxide anion and by raising the nonenzymatic glycosylation of proteins, as well as by activating various cellular transcription factors, which may affect cellular function and cause the pulmonary abnormalities mentioned.

Oxidative stress is generally believed to be a causative factor in chronic complications and may be measured on the basis of the level of thiobarbituric acid reactive substances (TBARS) and the activity of catalase ${ }^{6}$.
Hyperglycemia can even activate nuclear transcription factors, thus triggering an increase in the expression of inflammatory mediators. The combined effect of these mechanisms is to alter oxidant production, causing cellular oxidative stress and the resulting structural damage. Experimental studies showed that the pulmonary vascular resistance rises two weeks after the onset of DM and that hyperglycemia induces oxidative stress in lung tissue ${ }^{7}$.

Exposure to high concentrations of oxygen alters the respiratory tract in human beings and other animals, with deleterious effects on the pulmonary epithelium, pulmonary arterial tree, alveolar septa and also on the pleural space ${ }^{8}$.

Currently few studies demonstrate the use of oxygen, whether in small, medium or high concentrations, in diabetic patients elucidating the potential pulmonary structural alterations. Thus our study aims to evaluate pulmonary oxidative stress in a model of experimental diabetes submitted hyperoxia.

\section{Methods}

This study was approved by the Ethics Committee on the Use of Animals (CEUA/ PPGSD -UFMS) protocol number 686/2015.

Forty adult, male Wistar rats (Rattus norvegicus), aged 8 weeks were used, obtained from the animal colony, Centro de Ciências Biológicas e da Saúde (CCBS), Universidade Federal do Mato Grosso do Sul (UFMS). The animals were maintained under controlled conditions of lighting (12 hr day-night cycle) and temperature $(22 \pm 2 \circ \mathrm{C}$; relative humidity 40 to $60 \%$ ), with ad libitum access to food and water. These baseline conditions were kept during an initial adaptation period of 7 days. The animals were randomly divided into four groups of 10 animals. In each group, half of the animals were induced to diabetes (group 
experimental) and the other half was preserved as group control. Each group was exposed to a different oxygen concentration $(21,50,75$ and $100 \%$ ) for a 90 -minute exposure period.

\section{Induction of diabetes}

In 20 animals, following a 12-hour fast, streptozotocin, dissolved in a $20 \mathrm{mM}$

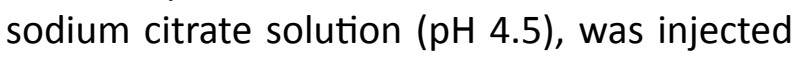
by the intraperitoneal route $(55 \mathrm{mg} / \mathrm{kg}$ i.p.; Sigma Chemical Co., St. Louis, MO, USA) within 15 minutes of preparation. Glucose measurements were made in 40 animals at the following times: zero time (fasting value), 8 hours, 24 hours, 48 hours and 72 hours following induction of diabetes. At the 72-hour time point, the animals were sacrificed. Blood glucose was determined using a colorimetric enzymatic assay (Accu-Chek Performa; Roche Diagnostics, USA). The animals that, at 72 hours after the application of streptozotocin developing blood glucose $>250 \mathrm{mg} / \mathrm{dl}$, were inserted into the experimental diabetes model $^{9}$.

\section{Experimental protocol for hyperoxia induction}

After the insertion of the diabetesinduced group into the experimental diabetes model, each of the four groups was randomly exposed to a given oxygen concentration. The animals were randomly allocated to the experimental protocol in glass chambers designed for the study $(33 \times 40 \times 30 \mathrm{~cm})$ and airtight closure effected by a cover/box seal using a silicon adhesive in conjunction with oxygen supplementation. Humidified oxygen was administered continuously, thus preventing carbon dioxide accumulation and maintaining the desired oxygen concentration at a constant level in all groups for the chosen period of 90 minutes. Control of the oxygen concentration inside the chamber was achieved with the aid of a calibrated flow meter (capacity of $15 \mathrm{~L} /$ $\mathrm{min}$ ) fed from a medical-grade oxygen cylinder. After exposure to oxygen the animals were euthanized by means of an i.p. injection of pentobarbital sodium. Lungs, pancreas and blood samples were collected (Figure 1).

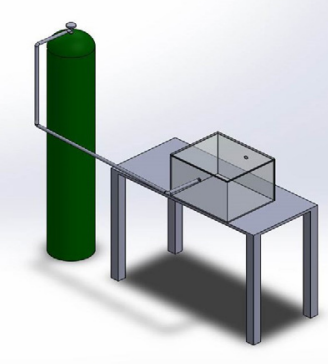

Figure 1 - Graphical representation of the glass box and oxygen cylinder used in the experiment.

Sample analysis procedure

To evaluate the oxidative stress in lung tissue and plasma, analytical procedures based on the TBARS method were utilized.

The pancreas and lungs used for histopathologic analysis were immersed in a buffered solution slowly infused of $10 \%$ formalin.

\section{Evaluation of oxidative stress}

Malondealdehyde (MDA) - a marker of oxidative stress, is one of the substances that react with thiobarbituric acid (TBA). The quantification of MDA concentration is considered a parameter to evaluate the rate of cellular lipoperoxidation. Thus the breakdown of polyunsaturated acids triggers the formation of malondialdehyde (MDA), which reflects the degree of peroxidation. Its absorbance at $535 \mathrm{~nm}$ was determined with 
the aid of a spectrophotometer ${ }^{10}$. To calculate the MDA concentration, an equation fitted to the absorbance curve generated by known MDA concentrations was used ${ }^{11-12}$.

\section{Histopathologic analysis}

The pulmonary and pancreatic tissue sections were analyzed by a pathologist who had no knowledge of the origin of the slides, via light optical microscopy, using a Leica DM5500B microscope and a Leica DFC495 digital microscope camera (8 megapixel) with Leica Application Suite (LAS) software version 4 , at a final magnification of $x 40$ from the panoramic viewer to the objective, in random fields, in two serial sections and converted into scores. The tissues were embedded in paraffin, sectioned at $4 \mu \mathrm{m}$ and stained with hematoxylin and eosin ( $\mathrm{H} \& \mathrm{E})$.

\section{Statistical analysis}

The comparisons between analysis times in relation to blood glucose or TBARS rate in tissue and plasma were performed by one-way repeated measures ANOVA, followed by Tukey's post-test. The comparisons between groups were made by means of Student's t-test. The Mann-Whitney test was used for the comparisons between diabetic and nondiabetic animals, in relation to pancreatic and pulmonary histopathologic alterations. The comparisons between the degree of oxidative stress in relation to pancreatic and pulmonary histopathologic changes were also performed by means of the Kruskal-Wallis test, followed by Dunn's post-test. Statistical analysis was carried out using the SigmaPlot version 12.5 statistical software, with the significance level set at 0.05 .

\section{Results}

The results of blood glucose in the animals according to the analysis time and the group (experimental or control) are presented in Table 1.

In the experimental groups, differences were seen in blood glucose in relation to time of analysis (one-way repeated measures ANOVA, 21\% group: $p=<0.001 ; 50 \%$ Group: $p=<0.001 ; 75 \%$ Group: $p=0.005$ and $100 \%$ Group: $p=<0.001$ ). The five animals in the $21 \%$ experimental group already had diabetes 24 hours after induction, unlike the other three experimental groups, in which the majority of animals only showed hyperglycemia (blood glucose $>250 \mathrm{mg} / \mathrm{dl}$ ) 72 hours after induction of diabetes (Tukey's post-test, $p<0.05$ ). In relation to the group of animals (diabetic or non-diabetic), significant differences were observed in blood glucose at the 72-hour time point following induction of diabetes in the eight subgroups, (Student t-test, $p<0.05$ ). Also, a difference in blood glucose could be observed between the two groups, demonstrating that the animals in the experimental groups could be inserted into the experimental diabetes model. The animals in the control groups also showed a significant difference in the blood glucose level in relation to time of analysis (one-way repeated measures ANOVA, 21\% Group: $p=0.036$; $75 \%$ Group: $p=<0.001$ and 100\% Group: $p=<0.001$ ), with the exception of the $50 \%$ Group $(p=0.061)$ that, although not statistically significant, approached the value $p \quad(p=<0.05)$. However, even though the animals in the control groups showed statistical significance, these variations in blood glucose at the times analyzed did not qualify for insertion into the experimental model of diabetes, since in this study animals that developed blood glucose $>250 \mathrm{mg} / \mathrm{dl}$ were considered hyperglycemic, which did not occur in any animal inserted into the control group. 
Table 1 - Results pertaining to blood glucose $(\mathrm{mg} / \mathrm{dl})$ in the animals, as a function of time and experimental group.

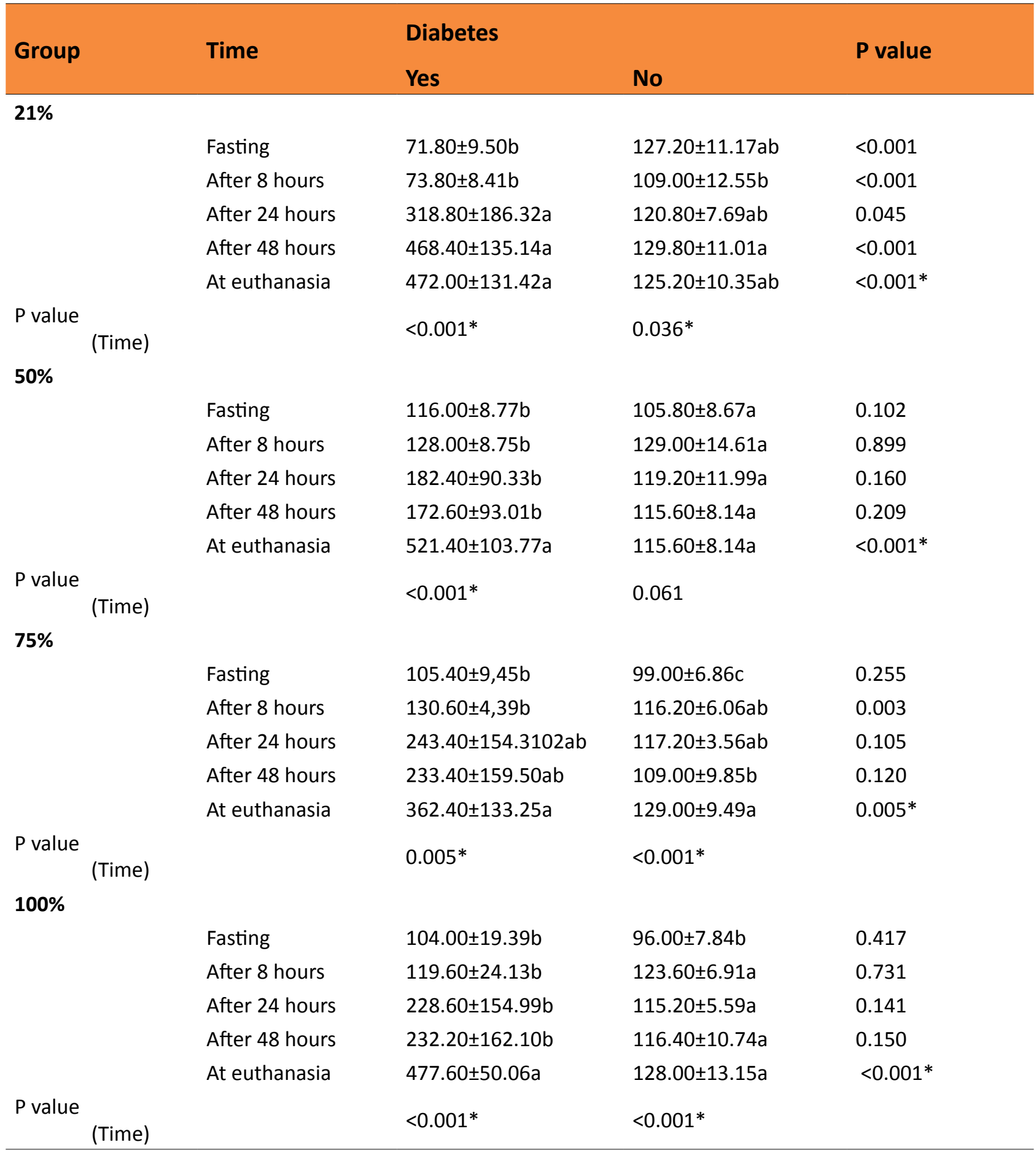

Results are presented as mean \pm standard deviation of the mean. Comparisons with respect to time: One-way repeated measures ANOVA, with Tukey's post-test. The various letters in the columns represent significant differences in blood glucose in the animals at various time points. Comparisons between diabetic and non-diabetic animals: Student's t-test. Statistical differences are indicated by $*, p<0.05$. 
Results relating to MDA concentrations in the animals' plasma and tissue, according to the experimental group and level of oxidative stress are presented in Table 2.

In the experimental groups a significant difference was seen in MDA concentration in lung tissue and plasma (paired Student's t-test, 21\% Group: $p=<0.001 ; 75 \%$ Group: $p=0.001$ and $100 \%$ Group: $p=<0.005)$, with the exception of the diabetic group exposed to $50 \%$ oxygen, in which no significant difference was observed ( $p=0.131$ for MDA concentration). In the animals of the control groups, significant differences were observed in the malondialdehyde concentration in the animals' lung tissue and plasma (paired Student's t-test,
21\% Group: $p=0.07 ; 50 \%$ Group: $p=0.008$ and 100\% Group: $p=0.003)$, with the exception of the control group exposed to an oxygen concentration of $75 \%$, which, although not statistically significant $(p=0.059)$, approached statistical significance $(p<0.05)$. The MDA concentration in lung tissue, in the groups of diabetic and non-diabetic animals, showed a significant difference in the 21 and 50\% groups ( $p<0.001$ and $p=0.043$ respectively), but in the 75 and $100 \%$ groups, no difference was observed in diabetic and non-diabetic animals $(p>0.05)$. The MDA concentration in the animals' blood plasma in the diabetic and non-diabetic groups presented no difference in any of the four groups ( $p>0.05)$.

Table 2 - Results in relation to the animals' plasma and tissue MDA concentrations (ng/ml), as a function of the experimental group and level of oxidative stress.

\begin{tabular}{|c|c|c|c|c|}
\hline \multirow{2}{*}{ Oxidative stress } & \multirow{2}{*}{ Location } & \multicolumn{2}{|c|}{ Diabetes } & \multirow{2}{*}{ P value } \\
\hline & & Yes & No & \\
\hline \multicolumn{5}{|l|}{$21 \%$} \\
\hline & Tissue & $2674.20 \pm 173.87$ & $1773.00 \pm 312.91$ & $<0.001$ \\
\hline & Plasma & $1256.00 \pm 113.29$ & $1133.80 \pm 73.71$ & 0.078 \\
\hline $\begin{array}{l}\text { P value } \\
\text { (Time) }\end{array}$ & & $<0.001^{*}$ & $0.007^{*}$ & \\
\hline \multicolumn{5}{|l|}{$50 \%$} \\
\hline & Tissue & $1578.40 \pm 135.47$ & $1813.40 \pm 171.96$ & 0.043 \\
\hline & Plasma & $1307.40 \pm 362.05$ & $1187.40 \pm 155.35$ & 0.515 \\
\hline $\begin{array}{l}\text { P value } \\
\text { (Time) }\end{array}$ & & 0.131 & $0.008^{*}$ & \\
\hline \multicolumn{5}{|l|}{$75 \%$} \\
\hline & Tissue & $1899.20 \pm 78.81$ & $1775.80 \pm 157.01$ & 0.115 \\
\hline & Plasma & $1401.20 \pm 134.87$ & $1415.60 \pm 280.99$ & 0.920 \\
\hline $\begin{array}{l}\text { P value } \\
\text { (Time) }\end{array}$ & & $0.001^{*}$ & 0.059 & \\
\hline \multicolumn{5}{|l|}{$100 \%$} \\
\hline & Tissue & $1892.20 \pm 164.32$ & $1751.80 \pm 84.40$ & 0.128 \\
\hline & Plasma & $1108.60 \pm 305.03$ & $1231.20 \pm 233.04$ & 0.495 \\
\hline $\begin{array}{l}\text { P value } \\
\text { (Time) }\end{array}$ & & $0.005^{*}$ & $0.003^{*}$ & \\
\hline
\end{tabular}

Results are presented as mean \pm standard deviation of the mean. Comparisons between locations: paired Student's t-test. Comparisons between diabetic and non-diabetic animals: Student's t-test. Statistical differences are indicated by *, $p<0.05$. 
Pulmonary alterations are illustrated in Figures 2, 3 and 4, according to the group and the oxygen concentrations that the animals were exposed.

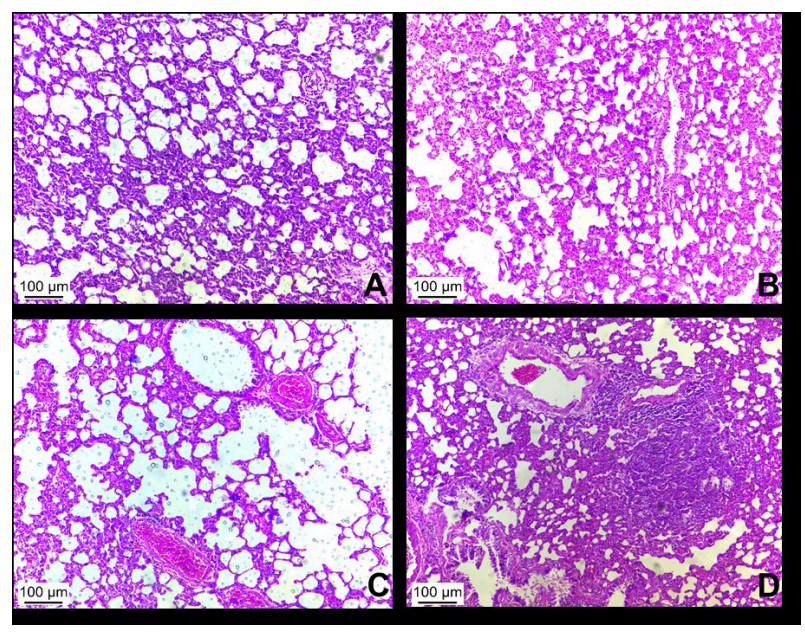

Figure 2 - Histological photomicrographs of lung sections from the control groups. (A) $21 \%$ control group showing minimal inflammatory infiltrate, absence of collapsed alveoli and absence of vessel wall thickening (B) $50 \%$ control group showing moderate inflammatory infiltrate, areas of focal edema and absence of vessel wall thickening (C) $75 \%$ control group showing presence of edema and inflammation (D) $100 \%$ control group showing presence of atelectasis, macrophages and inflammation in the $100 \%$ hyperoxic control group (H\&E stain, $x 10)$.

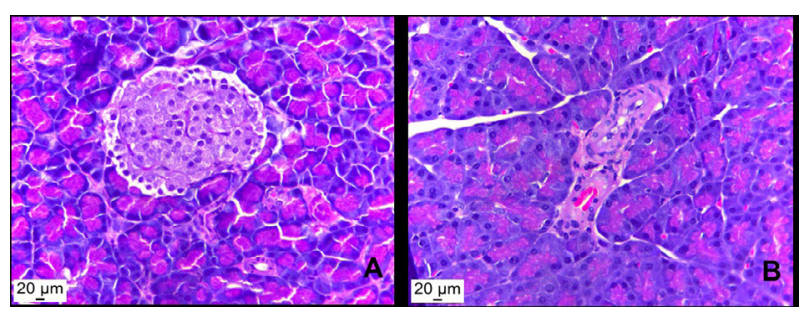

Figure 3 - Histological photomicrograph of pancreatic sections. (A) healthy, non-diabetic rat, showing normal pancreatic islet, which demonstrates no deformation or size reduction (B) diabetic rat, showing size reduction and deformation of pancreatic islet, due to destruction of the beta cells (H\&E stain, $x 40$ ).

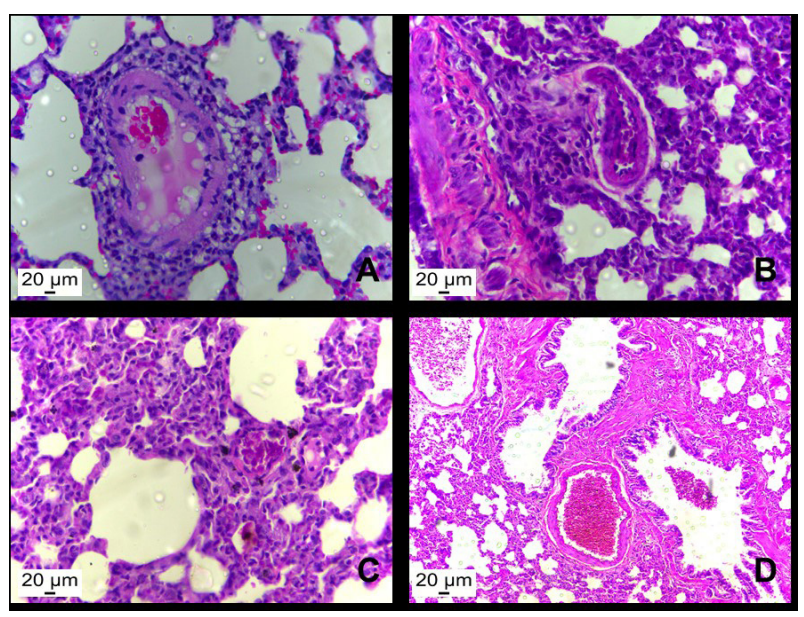

Figure 4 - Histological photomicrographs of lung sections from experimental groups. (A) $21 \%$ experimental group showing edema, congestion and inflammation (B) $50 \%$ experimental group showing atelectasis and inflammation (C) $75 \%$ experimental group showing presence of macrophages and inflammation (D) $100 \%$ experimental group showing presence of edema, hemorrhage, atelectasis, and inflammation as well as tissue fibrosis (H\&E stain, $\mathrm{x} 40$ ).

\section{Discussion}

In addition to hyperglycemia, polyphagia, polyuria and polydipsia were observed in the animals that received streptozotocin (data not shown), which demonstrates that the experimental diabetes model was effective. Induction of diabetes by streptozotocin destroys the beta cells within three days ${ }^{13}$, corroborating the data in this study. The diabetic animals showed higher serum glucose levels in comparison with nondiabetic animals. Other authors also confirmed hyperglycemia in animals in experimental diabetic groups when compared with animals that were not treated with streptozotocin ${ }^{14}$.

Oxidative stress is a consequence of the excessive presence of oxidants in relation to antioxidants ${ }^{15}$. Whereas oxidants 
at physiological levels play a beneficial role in energy production, in cellular signaling, and in host defense, oxidants in excess can lead to pathological changes ${ }^{16}$ and result in cell or tissue damage, disorders or disease. Oxidative stress involves molecules that are especially efficient oxidizing agents, known collectively as free radicals, including reactive oxygen species (ROS) and reactive nitrogen species (RNS). Various enzyme complexes generate ROS and RNS such as NADPH oxidase, myeloperoxidase, nitric oxide synthase, and superoxide dismutase ${ }^{15}$. Compounds that can be modified by the action of free radicals, such as lipids, proteins and sulfhydryl groups, are also used as indirect measures of oxidative stress. Oxidative stress may be evaluated by means of the enzyme activities involved in cellular redox balance, including superoxide dismutase, catalase, glutathione peroxidase and glutathione reductase, which convert superoxide radicals into peroxides or peroxides into water and hydrogen ${ }^{17}$. Much of what is reduced by superoxide dismutase (SOD) is converted into hydrogen peroxide ( $\mathrm{H} 2 \mathrm{O} 2)$. Hydrogen peroxide also can be reduced to water and oxygen through the reactions of the enzyme catalase and the enzyme glutathione peroxidase, which is a molecule with the capacity to dismutate ROS, becoming oxidized in the process. Glutathione (GSH) reacts with another GSH molecule, resulting in its oxidized form $\mathrm{GSSG}^{15}$.

Animal models with diabetes, which present a redox status similar to humans', are useful in the analysis of the mechanisms potentially involved in the relationship between diabetes and oxidative stress ${ }^{17}$. In our study, a model of diabetes was obtained in rats through the application of $55 \mathrm{mg} / \mathrm{kg}$ of streptozotocin. Streptozotocin preferentially accumulates in pancreatic beta cells via the Glut 2 glucose transporter and DNA fragments, and therefore selectively destroys the pancreatic beta cells.
A single high dose of STZ induces acute and massive injury of beta cells, leading to insulin deficiency with no autoimmune attack as in type 1 diabetes, or to insulin resistance, obesity and inflammation as in type 2 diabetes ${ }^{18}$.

Lipid peroxidation in tissues such as liver and kidney takes place in animals with diabetes induced by streptozotocin ${ }^{17}$. The diabetic rats showed a significant increase $(p<0.01)$ in the level of lipid peroxidation (oxidative stress) in the pancreas compared to healthy rats ${ }^{19}$. Consistent with this, a significant reduction in the level of SOD activity and increase in MDA content were observed in pancreas glands of the diabetic group $(p<0.01)$ compared with the control group ${ }^{14}$. In a study on rats with streptozotocin-induced diabetes, it was demonstrated that diabetes alters lung gene expression in Wistar rats, including the cell death/apoptosis gene ${ }^{20}$. Rats with diabetes induced by a single dose of $50 \mathrm{mg} / \mathrm{kg}$ streptozotocin exhibited a significant increase in hepatic lipid peroxidation, as observed on the basis of the elevated MDA level. In addition, the ORAC index (oxygen radical absorbance capacity), the reduced glutathione (GSH) level, the reduced oxidized glutathione ratio (GSH: GSSG) and catalase (CAT) activity were decreased in the diabetic rat liver. The TUNEL assay showed an increase in apoptotic cell death in the livers of these animals ${ }^{21}$. In using TBARS as a measure of lipid peroxidation in lung tissue, a significant increase was seen in the diabetic animals in comparison with the experimental group and control group (healthy animals). An increase in lipid peroxidation in hepatic tissue and blood in the diabetic group was also observed, but in this study an increase in the antioxidant enzyme SOD was demonstrated in the lung tissue of diabetic animals compared with control animals ${ }^{6}$. In our study, a significant difference in MDA concentration could be seen in the analyzed materials of most experimental groups. 
Valença et $a .^{22}$ measured the damage induced by oxidative stress in the lungs of Wistar rats by the quantification of TBARS. The authors observed that the increase in oxygen concentration was dependent on the 90 'dose $(p<0.001)$. In a study on the effects of hyperoxia on the lungs of immature rats ( 21 days old), it was identified that the longer the period of exposure to hyperoxia, the higher the MDA content and myeloperoxidase (MPO) activity in the animals' lung tissue in comparison with the control group of animals exposed to ambient air $^{23}$. In a study on adult male rats, an increase was seen in the level of pulmonary malondialdehyde and myeloperoxidase in rats exposed to a concentration of $95 \%$ oxygen for 48 hours while glutathione (GSH) levels decreased in comparison with animals exposed to ambient air for the same period of time ${ }^{24}$. In our study, a significant difference was also identified in the MDA concentration in the lung and plasma of the hyperoxic (100\%) animals. The increase in the level of MDA was identified in both the diabetes-induced hyperoxia group and in the control hyperoxia group. Reis et al. ${ }^{25}$ observed that hyperoxia (100\% oxygen for $24 \mathrm{~h}$ ) induced a decrease in the number of alveolar macrophages in the alveolar lumen, modified pulmonary histoarchitecture and raised the amount of red blood cells in the air spaces of the experimental group hyperoxia in relation to the control group. In the pulmonary histopathologic analysis of the hyperoxic control group, it was also possible to identify the presence of extensive abnormalities in lung architecture and inflammation in comparison with the other groups of control animals ( $p=0.014$ and $p=0.012$, respectively; data not shown) (Figure 3).

Clayton et $a .^{26}$ reported that the pulmonary inflammatory process can be induced by the key mechanism of tissue damage through oxygen toxicity in the lung.

Chronic hyperglycemia (glucotoxicity) plays a central role in $\beta$ cell failure, inducing deleterious effects on the density and function of $\beta$ cells, and creates a vicious cycle that contributes to the progressive loss of functional $\beta$ cells density. Although the sequence of events has not been fully mapped and the exact mechanisms involved in the loss of $\beta$ cells are unknown, various mechanisms - including generation of reactive oxygen species (ROS), the activation of endoplasmic reticular (ER) stress, the chronic upregulation of the hexosamine/SGIcNAc signaling pathway and the induction of pro-inflammatory cytokines in the islets are considered to negatively affect the $\beta$ cells. The $\beta$ cells are highly susceptible to oxidative stress because of an excess of ROS in the islet microenvironment in response to elevated concentrations of glucose and intrinsically low expression of antioxidant enzyme defense mechanisms ${ }^{27}$. It was possible to observe, in the course of the histopathological analysis of our study, a reduction in the size/area of the pancreatic islets in diabetic animals when compared with animals in the control group. $(p<0.05$, statistics not shown) (Figure 2$)$.

In a study on rats with streptozotocininduced diabetes, it was demonstrated that lung oxidative stress was significantly higher than in the control animals. In these diabetic animals, lung ultrastructural abnormalities were observed, shown by the increase in thickness of the basal lamina and alveolarcapillary membrane, along with pulmonary fibrosis. In the blood gas analysis, abnormalities in gas exchange were described in diabetic animals, manifested as a reduction in $\mathrm{PaO}_{2}$ and an increase in $\mathrm{PaCO}_{2}$, thus indicating a reduction in diffusion capacity ${ }^{28}$. In our study, it could not be shown all data concerning the histopathological analysis of lung tissue, but, despite the brief exposure period, some pulmonary abnormalities were identified, as the presence of inflammatory process in the hyperoxic and other experimental groups 
(Figure 4). The analysis of lung tissue in animals with streptozotocin-induced diabetes also showed increased thickness of the lung basal lamina. In addition, animal models showed that diabetic individuals have a deficit in protein expression, including surfactant protein $A$ and hydrophobic surfactant proteins $B$ and $C^{7}$.

In a study analyzing the effect of ventilation at different inspired fractions of oxygen and of allopurinol on lung ischemiareperfusion in rats, apparently contradictory data were obtained. In the group ventilated with $100 \%$ oxygen that used an antioxidant, better results were obtained, suggesting that the deleterious effect of high oxygen concentrations associated with ventilation during lung ischemia- reperfusion is basically due to oxidative stress, which seems that, when blocked, the oxygen in this concentration has some beneficial effects ${ }^{29}$.

In our study it was identified that at high concentrations of oxygen (75 and 100\%), no significant difference was seen in stress induced in lung tissue between diabetic and non-diabetic animals; the averages proved to be very close in the two groups, which differs from the results of the other studies presented. However, despite the new results shown, few studies in the literature have studied pulmonary oxidative stress in hyperoxia correlating with diabetes, suggesting that oxygen at these concentrations may not produce a totally deleterious effect, since as mentioned, hyperglycemia can produce oxidative stress in the lung tissue.

The animals exposed to $21 \%$ oxygen presented significant differences $(p<0.001$ ) and mean difference in relation to the group of animals (diabetic and non-diabetic). The 21\% diabetic group had a high level of MDA in lung tissue compared with MDA concentrations in the other diabetic groups.

Studies in the literature claim that hyperglycemia causes changes in the production of oxidants and may trigger oxidative stress in cells. It remains to be understood whether high concentrations of oxygen, even with the deleterious effects mentioned in this and other studies, is established with some beneficial effect in the presence of hyperglycemia. These new results show us the relevance of larger studies that emphasize the approach used in this research.

\section{- Conclusions}

Hyperoxia elicited an increase in the concentration of malondialdehyde in lung tissue and blood plasma and exerted deleterious effects on lung structure within the chosen time period of $90 \mathrm{~min}$. In pulmonary histopathology, tissue lesions occurred according to the higher concentration of oxygen in both groups (diabetic and nondiabetic). However, in diabetic animals the high concentrations of oxygen do not seem to reach these effects with respect to lipid peroxidation of the lung tissue.

\section{References}

1 American Diabetes Association. Diagnosis and classification of diabetes mellitus. Diabetes Care. 2014 Jan;37(1):S81-90. PMID: 9336756.

2 Whiting DR, Guariguata L, Weil C, Shaw J. IDF diabetes atlas: global estimates of the prevalence of diabetes for 2011 and 2030. Diabetes Res Clin Pract. 2011 Dec;94(3):31121. PMID: 22079683.

3 Davis TM, Knuiman $M$, Kendall $P, \mathrm{Vu} H$, Davis WA. Reduced pulmonary function and its associations in type 2 diabetes: the Fremantle Diabetes Study. Diabetes Res Clin Pract. 2000 Oct;50(2):153-9. PMID: 10960726.

4 Walter RE, Beiser A, Givelber RJ, O'Connor GT, Gottlieb DJ. Association between glycemic state and lung function: the 
Framingham heart study. Am J Respir Crit Care Med. 2003 Mar;167(6):911-6. PMID: 12623860.

5 Brownlee M. Biochemistry and molecular cell biology of diabetic complications. Nature. 2001 Dec;414(6865):813-20. PMID: 11742414.

6 Wietzycoski CR, Marchesini JCD, AlThemyat S, Meyer FS, Trindade MRM. Melhora do estresse oxidativo após duodenojejunostomia em um modelo experimental de diabete melito tipo 2. Arq Bras Cir Dig. 2016 Apr;29(1):3-7. PMID: 27683765.

7 Calles-Escandon J, Cipolla M. Diabetes and endothelial dysfunction: a clinical perspective. Endocr Rev. 2001 Feb;22(1):3652. PMID: 11159815.

8 Crapo JD. Morphologic changes in pulmonary oxygen toxicity. Annu Rev Physiol.1986:48(1):721-31. PMID: 3518622.

9 Peres GB, Juliano MA, Aguiar JA, Michelacci YM. Streptozotocin-induced diabetes mellitus affects lysosomal enzymes in rat liver. Braz J Med Biol Res. 2014 Jun;47(6):45260. PMID: 24820066.

10 Buege JA, Aust SD. Microsomal lipid peroxidation. Methods Enzymol. 1978;52:302-10. PMID: 672633.

11 Santos EB, Koff WJ, Grezzana Filho TJM, De Rosii SD, Treis L, Bona SR, Pêgas KL, Katz B, Meyer FS, Marroni NAP, Corso CO. Oxidative stress evolution of ischemia and reperfusion in kidneys under various degrees of hypothermia in rats. Acta Cir Bras. 2013 Aug;28(8):568-73. PMID: 23896835.

12 Uchiyama $M$, Mihara $M$. Determination of malonaldehyde precursor in tissues by thiobarbituric acid test. Anal Biochem.1978 May;86(1):271-8. PMID: 655387.

13 Karunanayake EH, Hearse DJ, Mellows G. The metabolic fate and elimination of streptozocin. Biochem Soc Trans. 1975;3(3):410-4. PMID: 124280.

14 Zheng S, Zhao M, Wu Y, Wang Z, Ren Y. Suppression of pancreatic beta cell apoptosis by Danzhi Jiangtang capsule contributes to the attenuation of type 1 diabetes in rats. BMC Complement Altern Med. 2016 Jan;16:31. PMID: 26819084.

15 Buresh R, Berg K. A tutorial on oxidative stress and redox signaling with application to exercise and sedentariness. Sports Med
Open. 2015 Dec;1(1):3. PMID: 27747840.

16 Okamura DM, Pennathur S. The balance of powers: Redox regulation of fibrogenic pathways in kidney injury. Redox Biol. 2015 Dec;6:495-504. PMID: 26448394.

17 Silva $M$, Lima WG, Silva ME, Pedrosa ML. Effect of streptozotocin on the glycemic and lipid profiles and oxidative stress in hamsters. Arq Bras Endocrinol Metabol. 2011 Feb;55(1):46-53. PMID: 21468519.

18 Cheng Y, Shen J, Ren W, Hao H, Xie Z, Liu J, Mu $Y$, Han W. Mild hyperglycemia triggered islet function recovery in streptozotocin-induced insulin-deficient diabetic rats. J Diabetes Investig. 2016 Jul;1-12. PMID: 27184687.

19 Sharma $P$, Bhardwaj $P$, Singh R. Administration of lactobacillus casei and Bifidobacterium bifidum ameliorated hyperglycemia, dyslipidemia, and oxidative stress in diabetic rats. Int J Prev Med. 2016 Aug;7:102. PMID: 27625767.

20 van Lunteren $E$, Moyer $M$, Spiegler S. Alterations in lung gene expression in streptozotocin-induced diabetic rats. BMC Endocr Disord. 2014 Jan;14:5. PMID: 24423257.

21 Oyenihi OR, Brooks NL, Oquntibeju OO. Effects of kolaviron on hepatic oxidative stree in streptozotocin induced diabetes. BMC Complement Altern Med. 2015 Jul;15:236. PMID: 26179065.

22 Valença SDS, Kloss ML, Bezerra FS, Lanzetti $M$, Silva FL, Porto LC. Effects of hyperoxia on Wistar rat lungs. J Bras de Pneumol. 2007 Nov-Dec;33(6):655-62. PMID: 18200365.

23 Wu CY, Yue F, Li M, Zhang LP, Whang J, Guo $X Y$. Effects of hyperoxia on inflammatory response in lung of infantile rats. Zhonqquo Wei Zhong Bing Ji Jiu Yi Xue. 2010 Jul;22(7):389-92. PMID: 20663297.

$24 \mathrm{Hu} \mathrm{X,} \mathrm{Guo} \mathrm{C,} \mathrm{Sun} \mathrm{B.} \mathrm{Inhaled} \mathrm{nitric} \mathrm{oxide}$ attenuateshyperoxicandinflammatoryinjury without alternation of phosphatidylcholine synthesis in rat lungs. Pulm Pharmacol Ther. 2007;20(1):75-84. PMID: 16480908.

25 Reis RB, Nagato AC, Nardeli CR, Matias IC, Lima WG, Bezerra FS. Alterations in the pulmonary histoarchitecture of neonatal mice exposed to hyperoxia. J Pediatr. 2013 May;89(3):300-6. PMID: 23669216.

26 Clayton CE, Carraway MS, Suliman HB, Thalmann ED, Thalmann KN, Schmechel DE, Piantadosi CA. Inhaled carbon monoxide and 
hyperoxic lung injury in rats. Am J Physiol Lung Cell Mol Physiol. 2001 Oct;281(4):94957. PMID: 11557599.

27 Alejandro EU, Gregg B, Blandino-Rosano M, Cras-Mèneur $C$, Bernal-Mizrachi E. Natural history of $\beta$-cell adaptation and failure in type 2 diabetes. Mol Aspects Med. 2015 Apr;42:19-41. PMID: 25542976.

28 Forgiarini Junior LA, Kretzmann NA, Porawski $M$, Dias AS, Marroni NAP. Estresse oxidativo e alterações estruturais pulmonares no diabetes mellitus experimental. J Bras Pneumol. 2009 Aug;35(8):788-91. PMID: 19750332.

29 Silva FM, Silveira RJ, Hallal ALLC, Wilhelm Filho D, Cardoso JJD, ACBC-SC, Leão LEV, TCBC-SP. Efeito da ventilação com diferentes frações inspiradas de oxigênio e do alopunirol na isquemia-reperfusão pulmonar em ratos. Rev Col Bras Cir. 2004 Sept-Oct;31(5):291-8. doi: 10.1590/S010069912004000500005.

\section{Acknowledgements}

To Dr. Elaine Silva de Pádua Melo, technician, Laboratório de Carcinogênese e Modelo Animal de Doença; Anderson Fernandes da Silva, Fellow PhD degree, Program in Health and Development; Mariana Vantini Soares (CNPq Scholarship), medical student and research trainee, for all their support and assistance, and to Dr. Priscila Pizzo for her assistance in the histopathological analyses.

\section{Correspondence:}

Letícia Alves Paiva

Avenida Norte, 1098

79011-322 Campo Grande - MS Brasil

Tel.: (55 67)99243-7207

lehalves13@hotmail.com

Received: Mar 16, 2017

Review: May 15, 2017

Accepted: June 19, 2017
Conflict of interest: none

Financial source: CAPES

${ }^{1}$ Research performed at Laboratory of Carcinogenesis and Experimental Animal Model, Universidade Federal do Mato Grosso do Sul, Campo Grande-MS, Brazil. Part of Master degree thesis, Postgraduate Program in Health and Development, West Central Region, Universidade Federal do Mato Grosso do Sul (UFMS), Campo Grande-MS, Brazil. Tutor: Iandara Schettert Silva. 